\title{
Barriers to and facilitators for implementing an office ergonomics programme in a South African research organisation
}

\author{
Bauba S. Koma ${ }^{\mathrm{a}, *}$, Anne-Marie Bergh ${ }^{\mathrm{a}, \mathrm{b}}$, Katia M. Costa-Black ${ }^{\mathrm{a}, \mathrm{c}}$
}

\author{
${ }^{a}$ School of Health Systems and Public Health, University of Pretoria, Private Bag X323, Arcadia, 0007, \\ Pretoria, South Africa \\ b SAMRC Unit for Maternal and Infant Health Care Strategies, University of Pretoria, Private Bag X323, \\ Arcadia, 0007, Pretoria, South Africa \\ ${ }^{c}$ Program of Ergonomics and Biomechanics, New York University School of Medicine, 63 Downing Street, \\ New York, USA \\ * Corresponding author. \\ E-mail addresses: bauba.koma@yahoo.com (B.S. Koma), anne-marie.bergh@up.ac.za (A.-M. Bergh), \\ kcb218@nyu.edu (K.M. Costa-Black).
}

\section{Abstract}

The focus of this study was on the possibility of implementing an office ergonomics programme as part of a broader workplace health initiative at a South African research organisation. We explored the perspectives of actors in the workplace regarding organisational barriers and facilitators to implementing ergonomic interventions. This qualitative study presents the perspectives of three workplace actor groups: operational managers $(n=4)$; health and safety representatives $(n=9)$; and office employees $(n=4)$ who were involved in a previous ergonomic assessments that proposed several corrective and preventive actions. Eight factors emerged as either barriers or as simultaneous barriers and facilitators to the implementation of proposed ergonomic interventions. These are: organisational culture; information and specialist support; funding; support from operational managers; attitude towards changes; general organisational awareness; individual knowledge 
of ergonomics; and support from colleagues. This study is one of the first in South Africa to investigate the perspectives of workplace actors in an office setting with regard to factors that influence implementation of ergonomics initiatives to reduce work-related musculoskeletal disorders.

Keywords:

Musculoskeletal disorders

Office ergonomics

Barriers and facilitators

Ergonomic intervention

\section{Introduction}

The World Health Organization (WHO) recommends managing musculoskeletal disorders (MSDs) in the workplace through ongoing health promotion, mitigation and prevention activities. These interventions should aim to change behaviour regarding pain and health, as well as improve working conditions (Burton 2010). The WHO proposes a 'healthy workplace framework and model' that encompasses a broader view of health in the workplace to include the idea of addressing of physical and psychosocial problems and of promoting access to healthcare resources and community support. This model is thus essential for any business interested in maintaining a healthy and productive workforce, especially when considering MSDs, which are multi-factorial and becoming increasingly common (Whysall, Haslam, and Haslam 2006). The model has, furthermore, been used as a business tool and scientific guide to advance healthy workplace initiatives worldwide (Burton 2010). 
In the United States, the Centers for Disease Control and Prevention (CDC) developed a similar model that lists coordinated and comprehensive strategies designed to meet the health and safety needs of all employees. These strategies include programmes, policies, benefits, environmental supports and links to the surrounding community (CDC 2013). More recently, the CDC and the National Institute of Occupational Safety and Health (NIOSH) revised the model to align with a new initiative called the Total Worker Health (TWH) framework (NIOSH 2016). The TWH framework incorporates ergonomics, which could be tailor-made to integrate with a company's exisiting health and safety activities (NIOSH 2016).

As a specific model for best practice in office ergonomics, Chim (2014) proposed FITS, an acronym for four components that need to be addressed for an office ergonomics programme to be effective. These components are Furniture evaluation and selection,

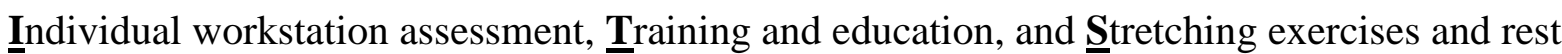
breaks. Other key aspects related to a FITS programme are: understanding and ensuring a fit between the interaction of individuals and their work environment and task; suitable quality of delivery that fits the desired purpose; and describing a fit healthy person in good physical condition.

In general, effective workplace health and office ergonomics programmes share the following core principles:

- an initial needs assessment or hazards identification stage (Sparling 2010; International Association of Oil and Gas Producers 2010);

- upper management support and commitment, for example through implementation of a policy (European Agency for Safety and Health at Work 2007; Shain and Kramer 2004); 
- encouraging and ensuring employee engagement and involvement usually using a participatory approach (Zungu and Setswe 2007; Hallowell 2010);

- integrating the programme into existing organisational operations (Goetzel et al. 2007; Chim 2014); and

- monitoring and evaluation (Babu et al. 2013; Goetzel et al. 2007; Hallowell 2010 ; International Association of Oil and Gas Producers 2010).

While we know these principles are important for successful implementation, there is still a lot to learn about how they may vary in different organisational settings. In recent decades, implementation research has largely focused on organisational context, including inner and outer contextual factors (Damschroder et al. 2009). Inner context describes structural and cultural factors, such as size, leadership and organisational climate, while outer context considers inter-organisational influence, environment and politics (Damschroder et al. 2009). Implementation studies point out to several important factors predicting receptivity for innovations and knowledge management capabilities within an organisation, including a supportive organisational culture, good managerial and employer-employee relations and clarity of goals and priorities. Manager and employee opinions about innovations and their readiness to change may also be important in achieving a more receptive context for change (Verbeke et al. 1998).

The implementation of workplace health programmes may encounter barriers at multiple organisational levels, for example:

- lack of management commitment and support (Whysall, Haslam, and Haslam 2006);

- poor management attitude towards implementation (Whysall, Haslam, and Haslam 2004); 
- lack of employee support (Masi and Cagno 2015);

- lack of financial resources (Rothmore, Aylward, and Karnon 2015);

- prioritisation of operations and/or other occupational health and safety needs over ergonomic needs (Fassier et al. 2015; Masi and Cagno 2015);

- lack of knowledge of ergonomics (Masi and Cagno 2015; Whysall, Haslam, and Haslam 2004);

- lack of or ineffective communication and information (Fassier et al. 2015; Masi and Cagno 2015);

- lack of time or inadequate time dedicated to ergonomics implementation (Masi and Cagno 2015);

- non-supportive organisational culture (Rothmore, Aylward, and Karnon 2015; Whysall, Haslam, and Haslam 2004); and

- lack of specialist support (van Eerd et al. 2010).

Facilitators for the implementation of workplace health programmes include: management support and commitment; good communication and information; knowledge of ergonomics, in particular knowledge of the benefits of the intervention; and change of management (i.e. a new manager may have a more favourable attitude towards implementation) (Fassier et al. 2015; Rothmore, Aylward, and Karnon 2015; Van Eerd et al. 2010; Whysall, Haslam, and Haslam 2006). A recent literature review found that management commitment was the most important facilitator towards successful implementation of a workplace health programme, because management is able to ensure the availability of the required resources (BurgessLimerick 2018).

The challenges in implementing office ergonomics programmes may differ in industrially developed and developing economies. In countries with developing economies, the 
implementation of ergonomics interventions may be limited by a general lack of knowledge of ergonomics, the assumption that ergonomics is a luxury and not part of a comprehensive approach to workplace safety and health, and a limited number of qualified ergonomists (Scott, Kogi, and McPhee 2010; Guimarães et al. 2014). In developing countries such as India, office ergonomics is largely disregarded. The health of the Indian workforce is plagued by MSD symptoms due to poor workstation design, child labour and the absence of laboursaving equipment for rural women engaged in agricultural work (O’Neill 2005).

In South Africa, the Occupational Health and Safety Act 85 of 1993 governs health and safety practices in the workplace. Section 16 of this Act charges every chief executive officer with the duty "to provide and maintain, as far as reasonably practicable, a working environment that is safe and without risk to the health of his employees" (Republic of South Africa 1993). Risks to health include ergonomic risk factors that can lead to the development of MSDs among office workers using computer workstations (Robertson et al. 2009).

We conducted this study at a South African research organisation (henceforth called "the Organisation") that has adopted the OHSAS 18001 management system. Following 115 cases of MSDs reported by office workers between 2008 and 2011, the Organisation conducted a survey to determine the prevalence of MSDs and other office ergonomics-related disorders among all office workers. The survey revealed five different health outcomes: lower back pain $(33 \%)$; eyestrain $(37 \%)$; headache $(24 \%)$; sore wrist $(12 \%)$; and other work-related injuries (11\%) (Research Organisation 2011). In this study, we explored the perspectives of employees and managers (actors in the workplace) regarding barriers and facilitators for implementing office ergonomics initiatives within the Organisation with a view to making recommendations for successful implementation of ergonomic interventions in an office workspace. As South Africa is a developing country this information can provide important guidance for other developing countries trying to identify key success parameters for 
implementing a comprehensive ergonomics programme. In addition, this information could also provide important comparative data regarding how previous models of implementing ergonomics programmes emanating from industrially developed countries, may or may not apply to developing countries.

\section{Methodology}

A qualitative research design was appropriate for the exploratory nature of this study. For this purpose, open-ended individual and focus group interviews with different groups of workplace actors was the choice of methodology to elicit understandings of the results of previous office ergonomic assessments and other related efforts undertaken in the Organisation and to make appropriate recommendations.

The study was approved by the Research Ethics Committee of the Faculty of Health Sciences, University of Pretoria (study reference number 63/2015). Written permission was obtained from the Organisation's Health and Safety Committee.

\subsection{Study setting}

The Organisation had more than 2000 employees distributed across various sites throughout South Africa. The setting for this study was the main premises of the Organisation, which is the largest in terms of geographical size and employee numbers. 


\subsection{Sampling}

Three organisational units with the highest number of office ergonomics assessments in the previous four years were purposively sampled for the study. We included four operational managers from these units and four employees whose offices had previously been assessed and who were still working in the same or a similar position. The selection of participants was based mainly on the number of recommendations made for purchasable equipment and/or furniture, as well as the date on which the assessment was conducted. Where a potential participant was unavailable or unwilling, the next eligible employee was selected. We also invited all 115 health and safety $(\mathrm{H} \& S)$ representatives in the twelve organisational units at the main premises to participate. Nine H\&S representatives from seven different organisational units volunteered and were included in the study.

\subsection{Data collection}

The first author, who was employed at the Organisation, collected the data. He conducted individual interviews with the four operational managers and the four employees as well as two focus group interviews with five and four H\&S representatives, respectively. In the health and safety management structure of the Organisation, H\&S representatives are all on the same hierarchical level and this made it easier for them to voice their independent opinions during discussions without fear of reprisal.

All participants provided written informed consent. Interviews were guided by a semistructured interview schedule and were audio-recorded. Interviews with operational managers and $H \& S$ representatives looked into understandings and knowledge of workplace health and office ergonomics, previous experiences in dealing with office ergonomics challenges, and 
attitudes towards the implementation of office ergonomics initiatives. Topics discussed with individual employees included a review of previous office ergonomic assessments, the discussion of the ergonomics assessment report(s) with the operational manager, and the implementation of recommendations emanating from the assessments. All interviews ended with an exploration of perceptions of barriers and facilitators to the implementation of office ergonomic recommendations.

\subsection{Data management and analysis}

All audio-recordings were transcribed verbatim. A manual content analysis was done inductively (Hsieh and Shannon 2005). The first round of the analysis focused on the manifest content. The first author analysed the data for the three participant groups separately (employees, operational managers, $H \& S$ representatives) and identified potential categories and themes. In the second phase, he did further coding of the data to allow for latent content analysis. To minimise subjectivity, the second author acted as an additional analyst for identifying latent content. The two data analysts then compared the themes for different participants and groups and synthesised them according to their underlying meaning. We used this synthesis to develop a framework for identifying barriers and facilitators for the implementation of office ergonomics interventions in the Organisation.

\subsection{Validity of the study}

Purposive sampling enabled the recruitment of participants who could provide rich information (Babbie and Mouton 2001). Triangulation was achieved by using two different data collection methods, namely individual and focus group interviews, and by collecting data from three different sources, namely employees, operational managers and H\&S 
representatives. The detailed description of participants' experiences and the inclusion of direct quotations in this report enhance transferability to other settings (Shenton 2004; Creswell 2009). Member checking of the developed themes was done with H\&S representatives at two meetings. Representatives had the opportunity to provide inputs and confirm the feasibility of the interpretation of the findings (Creswell 2009).

The subjectivity of the first author working at the Organisation is acknowledged and thus reflexivity played an important role in participant recruitment and data collection. $\mathrm{He}$ continuously reflected on his position as both an insider and a researcher. His position as the occupational hygienist who had also conducted the previous office ergonomic assessments gave him some legitimacy and facilitated access to the study participants. Participants are sometimes more open and forthcoming about sharing information with an insider researcher (Dwyer and Buckle 2009). To minimise underreporting due to fear of exposure, all participants received written reassurance of confidentiality in an information leaflet accompanying the informed consent form. All individual interviews were conducted behind closed doors at a location selected by each individual participant. Further attempts to minimise subjectivity included the use of non-leading, open-ended questions, even while probing, and a conscious focus on the scope of the study rather than on previous knowledge and assumptions about the Organisation. The use of a second data analyst has already been mentioned.

\section{Findings}

The findings are presented in three subsections: participants' perspectives of prioritisation in implementation; a synthesis of barriers and facilitators in office ergonomics interventions; 
and a proposed heuristic tool to support office ergonomics initiatives, based on the identified barriers and facilitators.

\subsection{Participants' perspectives of prioritisation in implementation}

Employees and H\&S representatives suggested that operational managers applied some level of prioritisation when making decisions regarding the implementation of office ergonomics interventions, such as the purchase of office equipment. Delays in acquiring purchasable items were ascribed to a combination of factors: cost of required item(s); operational needs with financial implications; and operational managers' perception of the importance of a recommendation. The perceived hierarchy of managers' prioritisation of purchasable recommendations fell into two categories: those with no reported cases of MSD and those with reported cases. Table 1 provides a summary of the perceived prioritisation. 
Table 1. Prioritisation of office ergonomics recommendations by operational managers.

\begin{tabular}{|c|c|c|}
\hline & Prioritisation & Example \\
\hline \multicolumn{3}{|c|}{ GROUPS WITHOUT MUSKULOSKELETAL DISORDER CASES: } \\
\hline \multicolumn{3}{|c|}{ 1. Operations needs requiring financing: } \\
\hline 1.1 & $\begin{array}{l}\text { Other outstanding operational needs: } \\
\text { recommendations postponed }\end{array}$ & $\begin{array}{l}\text { "In a laboratory environment I think the cost of the equipment and the sort of stuff that we need to keep the lab running is actually so heavy that } \\
\text { they can't really ... there is really no allowance to spend too much on offices. For instance, I had to buy a beaker ... and a beaker costs one } \\
\text { thousand rand. So if they had to choose between a beaker and a chair, the chair is going to lose." (H\&S rep) }\end{array}$ \\
\hline 1.2 & $\begin{array}{l}\text { No other outstanding operational needs: } \\
\text { recommendations implemented }\end{array}$ & $\begin{array}{l}\text { "You [occupational hygienist] suggested that our chairs were not sufficient. Those took a while; we only got new ones last year [2014] ... So if } \\
\text { the employee requires something that might take something from the budget, it is always about the client first." (Employee) }\end{array}$ \\
\hline \multicolumn{3}{|c|}{ 2. Cost of office ergonomics recommendations: } \\
\hline 2.1 & $\begin{array}{l}\text { Higher costing: recommendation postponed (e.g. } \\
\text { office chair or high number of items required) }\end{array}$ & \multirow{2}{*}{$\begin{array}{l}\text { "If it is a small amount ... it is something that they can do, very quickly and easy. And I think that is why we got those steps [footrests]. The } \\
\text { right chairs were going to cost them slightly more, so they kept on postponing." (Employee) }\end{array}$} \\
\hline 2.2 & $\begin{array}{l}\text { Lower costing: recommendation implemented } \\
\text { (e.g. footrest) }\end{array}$ & \\
\hline \multicolumn{3}{|c|}{ 3. Operational manager's perceived level of importance of office ergonomic issue: } \\
\hline 3.1 & $\begin{array}{l}\text { Low importance or luxury: recommendation not } \\
\text { implemented (e.g. hands free headset; chairs) }\end{array}$ & $\begin{array}{l}\text { "In terms of the headphones their thinking is that, we've been using ... the handsets for so long and nothing bad has happened; it has worked, it } \\
\text { is a working formula. The reason that [we] would like that is just so that to make [our] lives easier." (Employee) }\end{array}$ \\
\hline & & $\begin{array}{l}\text { "But if someone says, 'Oh, I'd like a nice chair, because my chair is looking old', that's a different case. For me it's about the context of that } \\
\text { specific incident." (Manager) }\end{array}$ \\
\hline 3.2 & $\begin{array}{l}\text { High importance: recommendation implemented } \\
\text { (e.g. footrest) }\end{array}$ & $\begin{array}{l}\text { "I think for some reason the footrests ... for us short people, they were seen as a major thing that has to happen, because it happened immedi- } \\
\text { ately ... in a very short span of time." (Employee) }\end{array}$ \\
\hline \multicolumn{3}{|c|}{ 4. Nature of employee's work: } \\
\hline 4.1 & $\begin{array}{l}\text { Work in laboratory and office: recommendation } \\
\text { not implemented (e.g. laboratory technician) }\end{array}$ & $\begin{array}{l}\text { "And often like in our case ... because we are such a lot of people ... you end up with the old chairs that you pick up everywhere in the } \\
\text { Organisation ... But we use our offices too. I mean, you sit there and you need to do your worksheets and work on the computer, and ... we work }\end{array}$ \\
\hline \multirow[t]{2}{*}{4.2} & $\begin{array}{l}\text { Work in office only: recommendation } \\
\text { implemented }\end{array}$ & $\begin{array}{l}\text { as much in our offices as we work in the lab. So I think sometimes it is a bit neglected our office equipment ... regarding proper chairs. ” (H\&S } \\
\text { rep) }\end{array}$ \\
\hline & & "They will not spend out on any of those (laboratory) technicians, I'm telling you, no. Some of them have to share computers." (H\&S rep) \\
\hline \multicolumn{3}{|c|}{ GROUPS WITH REPORTED MUSKULOSKELETAL DISORDER CASES: } \\
\hline 1. & $\begin{array}{l}\text { Recommendations already perceived as highly } \\
\text { important: funds made available to ensure } \\
\text { purchase for implementation }\end{array}$ & $\begin{array}{l}\text { "But in general, if it is a medical issue, I don't think there will be an issue with cost." (H\&S rep) } \\
\text { "If it's something critical, obviously we'll find the budget for it." (Manager) }\end{array}$ \\
\hline
\end{tabular}


$\mathrm{H} \& \mathrm{~S}$ representatives also perceived office ergonomic issues as being less important than other occupational health and safety issues during their monthly inspections, as is demonstrated by the following statement: "I agree, there are so many issues in our environment that the chairs is actually the least of it" (H\&S rep). However, this perception did not indicate a lack of appreciation for the relevance and value of office ergonomics. When asked to rate the importance of office ergonomics on a scale of one to ten, one representative rated office ergonomics highly:

"I would put it as an eight, because people have to sit and normally they sit there for eight hours or a little bit less. But most of the time they sit behind the computer, so they need to have a good chair that gives them the support and everything it requires." (H\&S rep)

Given other health and safety issues, H\&S representatives prioritised office ergonomics during inspections as follows:

- Numerous other health and safety issues - office ergonomics excluded in inspections.

- Few other health and safety issues - office ergonomics likely to be included. "There are so many issues in our environment that the chairs is actually the least of it, but like he said, you check lighting and basically there is no fire hazard and what around, but basically you don't go and check if the chair is still working or if the bolt has fallen out or something like that. I mean, no, you don't." (H\&S rep)

"At times I overlook the office ergonomics because I'm more looking at the lab areas. So it is not intentional, but at times I just do forget to." (H\&S rep) 
3.2 Synthesis of barriers and facilitators for implementing office ergonomics interventions

Eight factors, each shared by at least two of the three participant groups, appeared to influence workplace actors' perceptions of support or non-support for implementation of required office ergonomics interventions or recommendations. We divided these factors into three types: organisational culture (a factor on its own); organisational factors (three factors); and psychosocial factors (four factors).

\subsubsection{Organisational culture}

Organisational culture refers to the unwritten but shared norms, beliefs, principles and ways of behaving towards office ergonomics within the Organisation, and the manner in which these may have influenced workplace actors' support for the implementation of office ergonomics initiatives.

"Once again it comes with the culture thing, where it is acceptable to take sick leave, or to go to the doctor, but it is not acceptable to spend R5000 on an office chair." (Manager)

Organisational culture was one of the two factors that all participant groups perceived as a barrier; the other barrier was a lack of general awareness of office ergonomics.

\subsubsection{Organisational factors}

Organisational factors could be further divided into the following categories: availability of information and specialist support; availability of funds; and support from the operational manager. 
Information and specialist support refers to workplace actors' awareness of existing office ergonomics support, and whether they were informed about available resources within the Organisation that could be used or mobilised to implement office ergonomics initiatives. Operational managers and employees were aware that the Organisation had an office ergonomics specialist and experienced the information they received from the specialist as a facilitator. $H \& S$ representatives were unaware of the availability of an office ergonomics specialist, which suggests that they tended to experience this factor as a barrier to office ergonomics implementation.

"I also think that it also has to do with having good support staff who know about the services that are available within the Organisation, and who can actually point us to say, there is somebody and we can get them to come and do an assessment."

(Manager)

"We need more kind of knowledge about it because we are limited ... I think there are a lot of things maybe we don't know." (H\&S rep)

Availability of funds refers to budgetary considerations and the degree to which they affect an operational manager's decision to support the implementation of office ergonomics initiatives: “... budget is an issue ... having money to buy new chairs, new computers, new screens ... budget is the biggest thing” (Manager).

Financial support aside, management support refers to how operational managers motivate and support the other two workplace actor groups in implementing office ergonomics initiatives. This is how H\&S representatives described this support:

"I never have problems; they [managers] always have approved what I've requested.” (H\&S rep)

"I think my manager also has a positive attitude when it comes to office ergonomics, and I think he is also supportive." (H\&S rep) 
$\mathrm{H} \& \mathrm{~S}$ representatives experienced management support as a facilitator and lack thereof as a barrier, whereas employees experienced management support as a facilitator.

\subsubsection{Psychosocial factors}

Psychosocial factors included attitude towards implementation, general organisational awareness of office ergonomics, individual knowledge of office ergonomics and support from colleagues.

The interpretation of employee attitudes towards the implementation of office ergonomics interventions was derived from the reports of employees on how they implemented changes that did not require funds and that they were able to accomplish on their own (e.g. workstation adjustments, workstation habits, posture changes and lifestyle habits). The interpretation of operational managers' attitudes was synthesised firstly from the managers' own responses about how they used resources to improve office ergonomics in their areas, and secondly from H\&S representatives' experiences and employees' views. All three participant groups experienced attitudes towards office ergonomics interventions as both a barrier and facilitator. Managers and employees explained that their attitudes were negatively influenced by other organisational requirements.

"Of course, there is always financial considerations when it comes to office ergonomics, I don't agree with it, but unfortunately when one is putting together one's budget and plans that is something that often has to take a backseat." (Manager)

"The clients will come first, because our business is them." (Employee)

The views and information provided by $H \& S$ representatives suggested specific attitudes towards their role in the implementation process of office ergonomics initiatives. 
“Most of us have been appointed by our managers, so it wasn't you volunteering to do it. You were actually just given it [the role]. ... You don't have a choice in the matter; you just had to accept it." (H\&S rep)

"I think the main barrier of the entire system of the EHS [environment, health and safety], we should not do it as employees ... because it takes a long time.” (H\&S rep) “The employees' attitude also. The employees, maybe they don't really care about which chair they are sitting on, as long as they continue to work." (H\&S rep)

General organisational awareness refers to the level of awareness of office ergonomics throughout the Organisation as perceived by all participant groups. One H\&S representative mentioned, "We just need as an organisation as a whole ... to create more safety and office ergonomics awareness” (H\&S rep). In addition to organisational culture, general awareness of office ergonomics was the only other factor perceived as a barrier to workplace actor support for implementation and never as a facilitator.

Workplace actors' individual level of knowledge of office ergonomics influenced their decision whether or not to support the implementation of office ergonomics interventions in different degrees. As with the availability of funds, an operational manager's decision, based on his or her knowledge of office ergonomics, may affect the abilities of the other two groups of workplace actors to support implementation. The experiences of operational managers and employees demonstrated that this factor tended to be a facilitator for the implementation of office ergonomics initiatives.

"First of all, I knew now that I had to, so it was something that I never thought about. So once I knew that this helps, then I just do it, now it's even second nature." (Employee)

"Because as soon as somebody has experienced the benefits of a proper office setup, you're sold, you have sold it to them." (Manager) 
H\&S representatives experienced a low level or lack of knowledge as a barrier.

"I think, like if you would provide the managers or the CAMs [competency area managers] like with enough information that for them to see the importance of office ergonomics, I think that would sort of like help to easily get support for a preferred funding, or the required funding. Because if you're going to go to your manager and say, 'I mean, I need an adjustable chair', the first question he is going to ask you: 'Why? Why not a normal chair?' But if he has that knowledge of how that would contribute to office ergonomics, I think that would play and be an important contribution as well.” (H\&S rep)

Support from colleagues refers to how colleagues behaved towards individuals affected by MSD and how they responded when asked about issues related to office ergonomics. In implementing employee-dependent office ergonomics interventions that required lifestyle changes, employees experienced support from colleagues as a facilitator: "Because it is an office full of ladies ... we are trying to eat healthy" (Employee).

H\&S representatives experienced support from colleagues as a facilitator and a lack of support as a barrier.

"When it comes to office ergonomics, if they see something there, they are my ears and eyes ... So I think just that the relationship with colleagues ... makes it easier." (H\&S rep)

\subsection{A heuristic tool for support of office ergonomics initiatives}

Based on the study findings, we developed a conceptual model to capture the interactions between workplace actors and their shared barriers and facilitators to office ergonomics interventions (Fig. 1). This model can be used as a visual heuristic tool by organisations 
similar to the study organisation, especially in African and other developing countries, to identify office ergonomics support structures, barriers and facilitators and to interrogate interactions and possible solutions to barriers and bottlenecks.

Fig. 1 is a graphic depiction of the following: (i) interactions between the eight factors and the three workplace actor groups; (ii) the interactions between the different workplace actors; and the (iii) interactions that support the implementation of office ergonomics initiatives. The arrows in the model represent the nature and direction of interactions. The frame around the diagram represents the organisational culture. The model inside the frame is divided into three distinct sections: psychosocial factors; workplace actors; and organisational factors. In the context or our study, the diagram suggests the following:

- All workplace actors perceived organisational culture to be the only barrier to support for implementation of office ergonomics initiatives. Organisational culture influenced all the other factors and all the workplace actors within the Organisation. As Organisational culture was perceived only as a barrier, it may therefore shift most other factors to become barriers rather than facilitators for implementation.

- The model suggests that psychosocial factors are fundamental to support for the implementation of office ergonomics interventions. If the psychosocial factors are favourable, an ergonomics intervention could be successfully implemented. Interactions between workplace actors may facilitate or limit successful implementation of office ergonomics initiatives. 




Fig. 1. Heuristic tool for the support of office ergonomics initiatives 


\section{Discussion}

Our study explored the views of potential adopters of an office ergonomics programme in South Africa in relation to the existing organisational climate for health and safety already in place. The perceived barriers and facilitators for ergonomics observed by the three groups of workplace actors were very similar and they reflect the main characteristics of the Organisation's environment. The similarity of our findings with research conducted in industrially developed countries confirms the universality of some barriers and facilitators in the implementation of office ergonomics programmes. Owing to the lower priority given to ergonomic issues in developing countries, turning barriers into facilitators may be more challenging.

We identified eight factors that were either barriers or facilitators for the implementation of office ergonomics interventions. None of the eight factors were exclusively mentioned as facilitators and two factors were reported as barriers only, namely organisational culture and general organisational awareness of office ergonomics. Study participants described the other six factors as either barriers or facilitators, depending on their perspective or circumstances.

In the study organisation, operational and other occupational health and safety needs were often placed ahead of office ergonomics needs, especially with regard to the allocation of financial resources. Whysall et al. (2006) also found that when production needs were prioritised over health and safety, there was a lack of resources for the implementation of health and safety initiatives. Similarly, a study in France that tested the feasibility of implementing a model to prevent work disability due to lower back pain found that decisions on time and human resource allocation prioritised production rates and other occupational risks over musculoskeletal ergonomic needs (Fassier et al. 2015). Although this lack of prioritisation for ergonomics is noted in our study and in others done in developed countries, 
further research is needed to identify how organisational structures in developing countries deal with the outer context pressure for improving workplace conditions and reducing MSDs (e.g. market competitiveness, community environment and politics).

In implementation research, 'adopters' who do not know enough about the innovation are not likely to support the innovation. A study on the adoption of ergonomics innovations among vegetable farmers in the United States divided the farmers into two main groups: potential adopters of the innovations and those not interested (Karsh, Newenhouse, and Chapman 2013). Similar to our study, Karsh and co-workers (2013) clearly demonstrated how lack of information support among potential adopters could be a barrier. Furthermore, farmers who were not interested in adopting innovations developed a negative attitude because they had no information support relating to the benefits and return on investment following the adoption of innovations (Karsh, Newenhouse, and Chapman 2013).

In an Australian study, managerial awareness based on tailored advice was an important implementation facilitator, while the most frequent barriers to the implementation of ergonomics advice were budgetary constraints, resources and general organisational awareness (Rothmore, Aylward, and Karnon 2015). Following interviews with 14 ergonomics consultants, Whysall, Haslam and Haslam (2004) found that clients' lack of understanding was one of the reasons why ergonomics recommendations were rarely implemented. These authors also highlighted managerial attitudes and beliefs as important factors that determined the successful implementation of recommendations.

A study in the United Kingdom highlighted the attitudes of both employees and managers as barriers to the implementation of interventions aimed at addressing occupational ill-health (Whysall, Haslam, and Haslam 2006). The findings of this study showed general employee resistance to change behaviour and managers' lack of appreciation of the importance of health and safety initiatives. In the current study, resistance and lack of appreciation of 
ergonomics also featured in relation to the attitudes of employees and managers towards the proposed ergonomics solutions and health and safety interventions in general.

The notion that lack of knowledge of ergonomics could be a barrier and influence individual attitudes towards the proposed ergonomic solutions - specifically at managerial levels, has been previously reported and is confirmed in our study. This key implementation factor should be well studied by organisations when designing and planning a comprehensive workplace health and ergonomics programme.

Furthermore, we identified the availability of specialist support in an organisation as a facilitator of implementation, and non-availability as a barrier. A study aimed at validating a framework for participatory ergonomics recommended the inclusion of an ergonomics specialist as part of the implementation team to provide expert advice and to empower managers and employees to carry out the interventions (Haines et al. 2002). In describing the implementation of an ergonomics intervention in the tyre manufacturing industry in Iran, Motamedzade (2013) also reiterated that having an ergonomics consultant available in the implementation team acted as a facilitator.

Participatory ergonomics approaches are recognised as an effective way to address a general lack of understanding about the benefits of ergonomics in reducing or preventing MSDs in both developing and developed countries (Abeeli et al. 2017). These approaches essentially work as a dissemination catalyst for ergonomic actions. A study on the implementation of a participatory ergonomics programme among eldercare workers found management support and financial resources as both barriers and facilitators, depending on presence and availability (Rasmussen et al. 2018). Similar findings were also found in another participatory ergonomics study conducted at four Dutch companies (Driessen et al. 2010). Most of the factors reported in these two studies were also identified in our study, for example, availability of financial resources, support from management, implementers' 
attitudes towards implementation, and support from colleagues. Participants in the Dutch study and the current study both reported organisational culture to be a barrier only and never a facilitator.

Organisational culture reflects the way things are done in an organisation (Verbeke et al. 1998). Regardless of whether an organisation exists in a developed or developing country, an improvement in organisational culture in favour of office ergonomics and overall health of all employees should be supported by a management system that can turn implementation barriers into facilitators. In light of our findings and other research findings, we suggest that more should be invested to change organisational culture, especially if these changes embrace prevention principles for MSDs, and the concept of TWH, targeting the many aspects of work conditions particularly important in developing countries such as South Africa. This might be the most essential principle for the implementation success of an office ergonomics programme. The findings may support the studied organisation to develop new strategies to change the attitudes and beliefs about ergonomics and contribute towards improving overall musculoskeletal health of its employees.

\subsection{Limitations of the study}

In the conceptualisation of the study methodology, certain trade-offs had to be made due to time and budget constraints. Participants were only recruited from the main site and the findings of this study may not be generalisable to all of the Organisation's sites. However, the other sites could probably identify with many of the findings of the current study given the potential transferability to these sites because of certain characteristics of the Organisation such as a central management and the existence of the same organisational units at other sites. 
Based on the alignment of the findings of this study with the literature, the collection of more data might have added very little to the eight factors identified.

In order to get to a manageable data set, the results of previous office ergonomics assessments were used to identify the most affected organisational units so that individual interviews could be held with affected employee and operational managers.

Although the intention was to recruit $H \& S$ representatives from all organisational units for participation in the focus group interviews, there were logistical challenges such as difficulties in coordinating time slots for the sessions that would suit representatives from different units. Despite this relatively poor interest, a number of different organisational units were represented in these interviews. In addition, there was a large overlap between the issues raised by the $H \& S$ participants and those that emerged in the interviews with the other two participant groups. The findings were presented at $\mathrm{H} \& \mathrm{~S}$ representative meetings of two organisational units and the utility and appropriateness of interpretations were discussed and confirmed.

\section{Conclusion}

Based on our findings, organisational culture seems to be the most important factor in the implementation of office ergonomics interventions because it affected the other seven factors. Where organisational culture acted as a barrier, all other factors were negatively affected, resulting in little to no support for the implementation of office ergonomics initiatives. In order for any organisation to successfully implement office ergonomics recommendations and to tap into the associated benefits, further insights should be gained into various strategies that are available to effect a culture change. 
Overall, this study revealed many barriers and facilitators at an organisational level, similarly described in the literature. Our study was unique because we considered the inner context of the organisational climate for ergonomics from the point of view of managers and employees in a setting not studied before in South Africa. The findings add knowledge about specific implementation factors that can contribute to the success or failure of ergonomic programmes. We outline a comprehensive approach to workplace ergonomics in a large organisation in a developing country. Our findings showed that evaluating the knowledge of all workplace actors before implementing an ergonomics programme is important. This knowledge will influence on the need for educational resources or the use of a participatory approach for capacitating and training managers, $H \& S$ representatives and employees. Our proposed heuristic model (representing the implementation barriers and facilitators reported by the three different workplace actors) can be used as a guiding tool to facilitate the design and development of more integrated actions between H\&S representatives, operational managers and employees, especially where office ergonomics programmes are not well developed. This integrated action for office ergonomics could support and improve a health and safety culture that embodies all the contemporary elements of workplace health such as ones proposed by TWH framework developed by NIOSH as well as the healthy workplace framework proposed by WHO.

\section{Acknowledgements}

We would like to thank all the participants for their willingness to take part in this study. The assistance of Dr Nico Claassen with the administrative organisation of the study is also acknowledged with thanks. A special acknowledgement goes to the late Dr Kirstie RendallMkosi who was involved in the early stages of the study. This project was part of the first 
author's master's study and was conducted at the organisation where he works. No other potential conflict of interest is reported. The views expressed in this paper are those of the authors and do not reflect the views of their employers. This research did not receive any specific grant from funding agencies in the public, commercial, or not-for-profit sectors.

\section{References}

Abeeli, A., Tamrin, S.B.M., Guan, N.Y., Karupphia, K., 2017. Potential of participatory ergonomic intervention approaches to reduce work-related musculoskeletal disorders among office workers: a review. Malay. J. Human Factors Ergon. 2 (2), 1-14.

Babbie, E.R., Mouton, J. (Eds.), 2001. The Practice of Social Research, eight ed. Oxford University Press, Cape Town.

Babu, A.S., Madan, K., Veluswamy, S.., Mehra, R., Maiya, A.G., 2013. Worksite health and wellness programs in India. Prog. Cardiovasc. Dis. 56 (5), 501-507.

Burgess-Limerick, R., 2018. Participatory ergonomics: evidence and implementation lessons. Appl. Ergon. 68, 289-293.

Burton, J., 2010. WHO Healthy Workplace Framework and Model: Background and Supporting Literature and Practices. Geneva: World Health Organization. Available at: http://www.who.int/occupational_health/healthy_workplace_framework.pdf (Accessed 28 May 2018).

CDC (Centers for Disease Control and Prevention), 2013. Workplace Health: Making a Business Case. Available at: http://www.cdc.gov/workplacehealthpromotion/businesscase/index.html (Accessed 28 May 2018). 
Creswell, J.M., 2009. Research design: Qualitative, quantitative, and mixed methods approaches, third ed. SAGE Publications, Los Angeles, CA.

Chim, J.M., 2014. The FITS model office ergonomics program: a model for best practice. Work 48 (4), 495-501.

Damschroder, L.J., Aron, D.C., Keith, R.E., Kirsh, S.R., Alexander, J.A., Lowery, J.C., 2009. Fostering implementation of health services research findings into practice: a consolidated framework for advancing implementation science. Implement. Sc. 4, 50.

Driessen, M.T., Groenewoud, K., Proper, K.I., Anema, J.R., Bongers, P.M., van der Beek, A.J., 2010. What are possible barriers and facilitators to implementation of a participatory ergonomics programme? Implement. Sci. 5, 64.

Dwyer, S.C., Buckle, J.L., 2009. The space between: on being an insider-outsider in qualitative research. Int. J. Qual. Meth. 8 (1), 54-63.

European Agency for Safety and Health at Work, 2007. Office ergonomics. E-Facts 13. European Agency for Safety and Health at Work, Bilboa, Spain. Available at: https://osha.europa.eu/en/tools-and-publications/publications/e-facts/efact13/view (Accessed 28 May 2018).

Fassier, J., Durand, M., Caillard, J., Roquelaure, Y., Loisel, P., 2015. Results of a feasibility study: barriers and facilitators in implementing the Sherbrooke Model in France. Scand. J. Work Environ. Health 41 (3), 223-233.

Goetzel, R.Z., Shechter, D., Ozminkowski, R.J., Marmet, P.F., Tabrizi, M.J., Roemer, E.C., 2007. Promising practices in employer health and productivity management efforts: findings from a benchmarking study. J. Occup. Environ. Med. 49 (2), 111-130.

Guimarães, L.B.deM., Ribeiro, J.L.D., Renner, J.S., de Oliveira, P.A.B., 2014. Worker evaluation of a macroergonomic intervention in a Brazilian footwear company. Appl. Ergon. 45 (4), 923-935. 
Haines, H., Wilson, J.R., Vink, P., Koningsveld, E.A.P., 2002. Validating a framework for participatory ergonomics (the PEF). Ergonomics 45 (4), 309-327.

Hallowell, M., 2010. Cost-effectiveness of construction safety programme elements. Construction Management and Economics 28 (1), 25-34.

Hsieh, H.F., Shannon, S.E. 2005., Three approaches to qualitative content analysis. Qual. Health Res. 15 (9), 1277-1288.

International Association of Oil and Gas Producers, 2010. Establishing an ergonomics programme for computer usage in an office environment. The International Association of Oil and Gas Producers (OGP), London.

Karsh, B., Newenhouse, A.C., Chapman, L.J. 2013. Barriers to the adoption of ergonomic innovations to control musculoskeletal disorders and improve performance. Appl. Ergon. $44(1), 161-167$.

Masi, D., Cagno, E., 2015. Barriers to OHS interventions in small and medium-sized enterprises. Saf. Sc. 71, (Part C), 226-241.

Motamedzade, M., 2013. Ergonomics intervention in an Iranian tire manufacturing industry. Int. J. Occup. Saf. Ergon. 19 (3), 475-484.

NIOSH (National Institute for Occupational Safety and Health), 2016. Fundamentals of total worker health approaches: essential elements for advancing worker safety, health, and well-being. By Lee MP, Hudson H, Richards R, Chang CC, Chosewood LC, Schill AL, on behalf of the NIOSH Office for Total Worker Health. Department of Health and Human Services, Centers for Disease Control and Prevention, National Institute for Occupational Safety and Health. DHHS (NIOSH) Publication No. 2017-112. Cincinnati. Available at: https://www.cdc.gov/niosh/docs/2017-112/pdfs/2017_112.pdf (Accessed 28 May 2018). 
O’Neill, D., 2005. The promotion of ergonomics in industrially developing countries. Int. J. Occup. Saf. Ergon. 35 (2), 163-168.

Rasmussen, C.D.N., Lindberg, N.K., Ravn, M.H., Jorgensen, M.B., Sogaard, K., Holtermann, A., 2017. Process, barriers and facilitators to implementation of a participatory ergonomics program among eldercare workers. Appl. Ergon. 58, 491-499.

Republic of South Africa, 1993. Occupational Health and Safety Act 85 of 1993 (Act No.85 of 1993). Government Gazette 337(14918).

Research Organisation, 2011. Ergonomics Hazards Identification and Risk Assessment of Research Organisation's campuses. Unpublished internal report.

Robertson, M., Amick III, B.C., DeRango, K., Rooney, T., Bazzani, L., Harrist, R., Moore, A., 2009. The effects of an office ergonomics training and chair intervention on worker knowledge, behavior and musculoskeletal risk. Appl. Ergon. 40 (1), 124-135.

Rothmore, P., Aylward, P., Karnon, J., 2015. The implementation of ergonomics advice and the stage of change approach. Appl. Ergon. 51, 370-376.

Scott, P., Kogi, K., McPhee, B., 2010. Ergonomics Guidelines for Occupational Health Practice in Industrially Developing Countries. International Ergonomics Association (IEA) and International Commission on Occupational Health (ICOH), Darmstadt. Available at: http://www.icohweb.org/site/multimedia/pubblicazioni/ICOH\%20and\%20IEA\%20Ergo nomics\%20Guidelines\%20April\%202010.pdf (Accessed 28 May 2018).

Shain, M., Kramer, D.M., 2004. Health promotion in the workplace: framing the concept; reviewing the evidence. Occup. Environ. Med. 61 (7), 643-648.

Shenton, A.K., 2004., Strategies for ensuring trustworthiness in qualitative research projects. Educ. Inform. 22 (2), 63-75. 
Sparling, P.B., 2010. Worksite health promotion: principles, resources, and challenges. Prev. Chronic Dis. 7 (1), A25.

Van Eerd, D., Cole, D., Irvin, E., Mahood, Q., Keown, K., Theberge, N., Village, J., St. Vincent, M., Cullen, K., 2010. Process and implementation of participatory ergonomic interventions: a systematic review. Ergonomics 53 (10), 1153-1166.

Verbeke, W., Volgering, M., Hessels, M. 1998. Exploring the conceptual expansion within the field of organizational behaviour: organizational climate and organizational culture. J. Manag. Stud. 35(3): 305-329.

Whysall, Z. J., R. A. Haslam, and C. Haslam. 2004. Processes, barriers, and outcomes described by ergonomics consultants in preventing work-related musculoskeletal disorders. Appl. Ergon. 35 (4), 343-351.

Whysall, Z., Haslam, C., Haslam, R., 2006. Implementing health and safety interventions in the workplace: an exploratory study. Int. J. Ind. Ergon. 36 (9), 809-818.

Zungu, L.I., Setswe, K.G., 2007. An integrated approach to the prevention and promotion of health in the workplace: a review from international experience. S. Afr. Fam. Pract. 49 (6), 6-9. 